\title{
A Research on Interaction and Merging between Modern Manufacturing and Producer Services
}

\author{
Jiemei Zhang \\ Business Management Institute of Henan University, \\ Kaifeng, China \\ jiemei1226@163.com
}

\begin{abstract}
The paper defines modern manufacturing and producer services and analyzes the interaction mechanism between these two industries from the perspectives of professional labor division, outsourcing, the production value chain and the ecological community respectively. It reaches the conclusion that a merging mode of interaction is the future development for modern manufacturing and producer services, and that it is imperative to boost such a merging mode in the industrialization of China.
\end{abstract}

Keywords: modern manufacturing, producer services, outsourcing, interaction and merging.

\section{Overview of Modern Manufacturing and Producer Services}

\subsection{The Definition of Modern Manufacturing}

Modern manufacturing is a new concept raised during the economic restructuring of China. Proposals on Revitalizing Modern Manufcturing in Beijing, a document issued by Beijing municipal government in Feb., 2003, specified the tasks, objectives and measures of accelerating the development of modern manufacturing in Beijing in the years to come. Statistics Bureau of Beijing city, in accordance with the requirements of sustainable development, put forward the definition of and criteria for modern manufacturing, which was approved by the Statistics Bureau of the State.

Modern manufacturing refers to manufacturing armed with modern science and technology, or a combination of the two. In essence, it means to optimize and upgrade the structure of manufacturing sectors, and it include all the firms and enterprises involved in processing and reprocessing raw materials with high and latest technology. Modern manufacturing is featured by high technology and high added value. It attaches great importance to input of knowledge and technology and therefore into processing, equipment and materials, therefore the products are high in technical content and added value. Modern manufacturing is so closely associated with other sectors that it could largely propel the national economy and serve as an important backbone of the whole industry. It complies with the sustainable development in that it is energy efficient and environment friendly. 
Compared with traditional manufacturing, modern manufacturing puts more stress on the input of knowledge and technology and on the application of modern technology, manufacturing organization systems and management concepts in the whole industry organization system with high technical content, more added value and long industry chain, which boasts modern integration production, intensive knowledge and high efficiency.

\subsection{The Definition of Producer Services}

Some scholars and institutes defined producer services from the angle of service activities involved. The concept of producer service was firstly proposed by American economist H.Greenfield in 1966 when he was studying services sectors and their classification. In 1975, Browning and Singelman also used "producer services" and stated that the services include knowledge-intensive and client-oriented services in finance, insurance, law, taxes and brokerage. Hubbard and Nutter (1982), Daniels (1985) classified services into producer services and consumer services, with the former involving the areas beyond the latter, also including goods storage and distribution, office cleaning and security services. Howells and Green (1986) held that producer services include insurance, banking, finance and other business-related services such as advertising and market research, profession and science services such as accounting and law, research and development services for other companies. Hong Kong Trade Development Council (HKTDC) believes that producer services involve professional services, information and intermediary services, finance and insurance services and other trade-related services.

Some scholars and institutes define producer services from the angle of service functions. Gruble and Walker (1989), Coffer (2000) proposed that producer services neither aim for consumption nor yield products directly, instead, they are the input within the process, playing a role of intermediary for the production of other final products or services. They further pointed out that the producers mainly employ labor and knowledge capital as input sources, with output involving enormous services for labor and knowledge capital, and that producer services can contribute to the professionalization of production, expand capital-intensive and knowledge-intensive production and finally enhance the productivity of labor force and other production elements. Hansen $(1990,1994)$ indicated that producer services act as an intermediary, present both in upstream activities like research and development, and in downstream ones like market. United States Department of Commerce further divided these functions into two types, one being "allied producer services", responsible for the transactions between the headquarters with branches of foreignfunded producer services corporations (taking up 10\% of the total services), the other being "independent producer services" directly collaborating with foreign firms, private enterprises and foreign governments (taking up 90\% of the total services). According to Chinese scholars Zhong Yun and Yan Xiaopei (2005), producer services offer services to manufacturing, business activities and governmental management rather than individual consumers, and they do not directly engage in producing process or transformation, though they are the indispensable activity in any industry. 
Theoretically, producer services refer to the input services from the market into the producing process, which are employed for further production of the commodities and services. Producer services are the services bought by the producers from the given market and offered for production and business activities instead of individual consumers. They also means the externalization and marketization of services, a trend that internal sectors for producer services are separated from and independent of original enterprises with purposes of reducing costs, improving productivity and enhancing the professional levels of corporate management.

\section{The Mode of Interaction between Modern Manufacturing and Producer Services}

As a division of labor, producer services are originated from manufacturing, and have a kind of innate kinship with the latter. Producer services are intermediate knowledge input, with manufacturing sectors as their major consumers. They rely on the demands of the manufacturing and contribute to the industry upgrade of the manufacturing. In a nutshell, the two are mutually reliant and stimulative. Their interactive mode can be further divided into an alternative mode and a merging mode.

\subsection{The Alternative Mode of Interaction between Modern Manufacturing and Producer Services}

This mode is based on the outsourcing of services realized by the market mechanism. The outsource of services refers to the practices that original internal service sectors of the corporation operate independently, free from the control of the corporation or that the corporation seek services or resources from other professional enterprises instead of from its own internal sectors. The practices mainly include outsourcing of services. There is a tendency of resorting to market means during the development of services. Producer services were once conducted through non-market means by the producing sectors, while manufacturers could buy various producer services on the market with the emergence of numerous enterprises specializing in finance, marketing and consultancy.

Outsourcing of services is the main way manufacturers interact with service industries. Manufacturers outsource to professional services enterprises the services that are not directly related to production activities or corporate strategies, such as human resources management, accounting and logistics. Producer services enterprises will in turn expand and diversify their services in order to meet ever-increasing intermediate needs from manufacturers, and hence became more professionalized and larger in size.

Newly-independent services enterprises. These enterprises are originally the internal sectors of large-scale and powerful manufacturers, which grow with much more services capacities than needed by their own enterprises. Hence, the independent professional services enterprises provide services not only for their parent enterprises 
but for other enterprises. Examples can be found in the independent logistics company and mould designing company of Hair Groups.

These newly-independent services enterprises intensify the competition in the services industry, which boost the internal development of the industry and also contribute to the higher productivity of the manufacturers.

\subsection{The Merging Mode of Interaction between Modern Manufacturing and Producer Services}

In this mode of deep-level interaction between manufacturers and services enterprises appears a merging tendency characteristic of ambiguity in features of products, organization and products confines. The definite trends are services going industrialized and manufacturing services-oriented. See Figure 1.

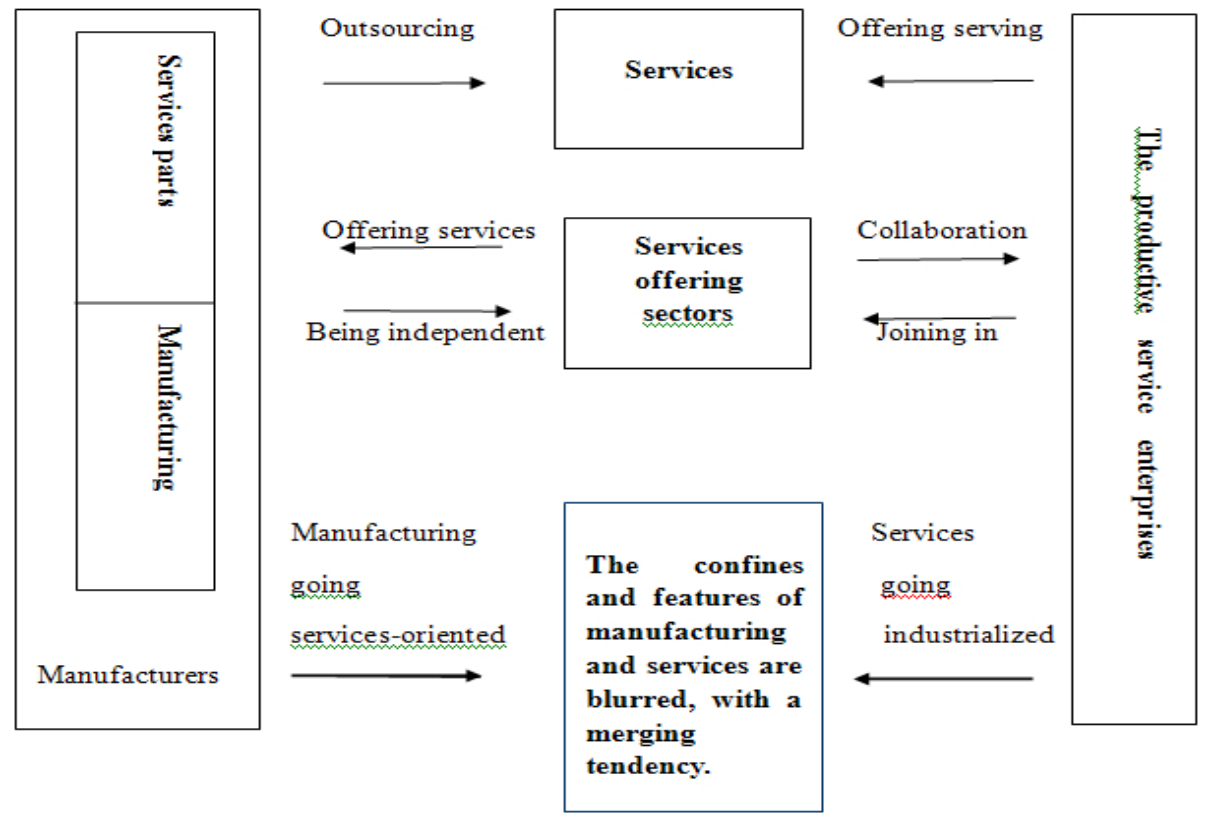

Fig. 1. The Merging Mode of Interaction Between Modern Manufacturing and Producer Services

Services enterprises became the dominant forces of economy with increased productivity and enlarged sizes fulfilled through industrialization of services. Against such a background, a number of large-sized aggressive producer services enterprises spring up and take up the top level of the industry chain, offering services to manufacturers and other services enterprises as well. They expand into other parts of the chain, turning into integrative services enterprises and providing comprehensive services to manufacturers. In the meantime, large-sized manufacturers gradually 
change from the pure manufacturing mode into a combination of manufacturing and producer services provision. Hence the growing ambiguity of the confines between manufacturers and services enterprises and a merging trend.

In general, the modes of interaction between manufacturers and services enterprises are not classified strictly according to their development phases, rather, they coexist. For instance, market-based practices like outsourcing of services and independent services sectors abound within the merging mode. The differences lie in the conditions under which the modes are applied. A case in point can be found in the newly-independent services enterprises that are operated mainly by large manufacturers instead of small or medium-sized ones. It is certain that only largesized manufactures capable of developing and offering services stand the chance to become services providers and join the mass producer services industry.

\section{The Interaction Mechanism between Producer Services and Manufacturers}

\subsection{The Interaction Mechanism Based on Labor Division and Outsourcing}

According to labor division theory held by the school of Classic Economics, outsourcing of producer services embodies the deep level of labor division and professionalization. Scholars from the school of New System Economics approach the matter with the theory of transaction costs. Coffey \& Drolet (1996) thinks that each enterprise is faced with a strategic choice of "DIY of Buy it" which will affect its costs structure, producing and organizing modes, its place in the region or even the structure of the economy. The fact is that enterprises always hope to have access to various recourses and capacities needed to yield products or services at the lowest possible costs so as to stay competitive. Outsourcing of producer services refers to the practice that enterprises get services though transactions with services providers on the market including manufacturers and services enterprises as well. Manufacturers once were the producers of a series of producer services such as internal R \& D sectors, wholesale and retail sectors and internal transportation facilities, which were all be provided by the headquarters of the enterprises (Coffey \& Polese, 1987). Through "vertical delegating", they now outsource services otherwise provided from inside. In services sectors, externalization is achieved through the so-called soft process of "horizontal delegating" (Michalak \& Fairbairn, 1993).

\subsection{The Interaction Mechanism Based on the Industry Chain}

The concept of "Industry Chain" was first proposed by American scholar, Michael Porter in 1985. He described how customers' value could be formed through a series of practices aimed for final products or services. He split the practices in half, namely, fundamental ones and supporting ones. Later he redefined the industry chain as a series of value-creating practices from fundamental raw materials and providers, 
through producers to the final products being consumed or transported. Porter (1998) verified that producer services enterprises permeate into every link of the industry chin of manufacturers and provide 5 interrelated input elements during the production process: (1) What products to be made; (2) How to make the products; (3) Process cooperation; (4) Other beneficial services; (5) Distribution. In his opinion, the process for an enterprise to create value can be broken up into different yet correlated valueadded activities such as design, production and sale which constitute the industry chain of the enterprise. Not every link can create value which actually comes from some certain activities known as strategic links. The competitive edge of an enterprise in one of these links determines its competitive power in the market. The economic competition of the world indicates that the competitive power of an enterprise relies less on processing and manufacturing than on producer services activities as the market competition intensifies.

From the perspective of the industry value chain, the functions of producer services are as follows: (1) producer services act as a channel through which labor, knowledge and technology capital enter the production process. The application of technology and knowledge in the manufacturing sectors are mainly fulfilled by means of the input of producer services like science and technology development, management consultancy and etc.; (2) producer services are the major sources of added value of products. It is said that in modern manufacturing, the profits of enterprises come mainly from the services links of design and marketing of products rather than processing; (3) producer services are the important approaches for enterprises to form product diversity and to compete with others in aspects other than prices.

\subsection{The Interaction Mechanism Based on Ecological Community}

The community is originally short for a biotic community, a collection of living species confined in a certain space during a specific period of time. There are three features about the biotic community. Firstly, living creatures in a given community are not scattered by accident, rather, there are complex relations between them in the forms of recycling of matters and transfer of energy. Therefore, there are some structures of constitution and nutrition in a given community. Secondly, biotic communities frequently change their appearances in a certain order as time goes by, with dynamic characteristics of constant development and evolution. Thirdly, the features of a community are not simply the sum of features of all the creatures within it.

In view of the theory of ecology, an economic community refers to a certain organization in the ecological system of economy, one being inherently related to another. The economic community consists of agricultural community, industrial community and modern services community, together with the indispensable manufacturing sub-community and producer services sub-community. See Figure 2. 


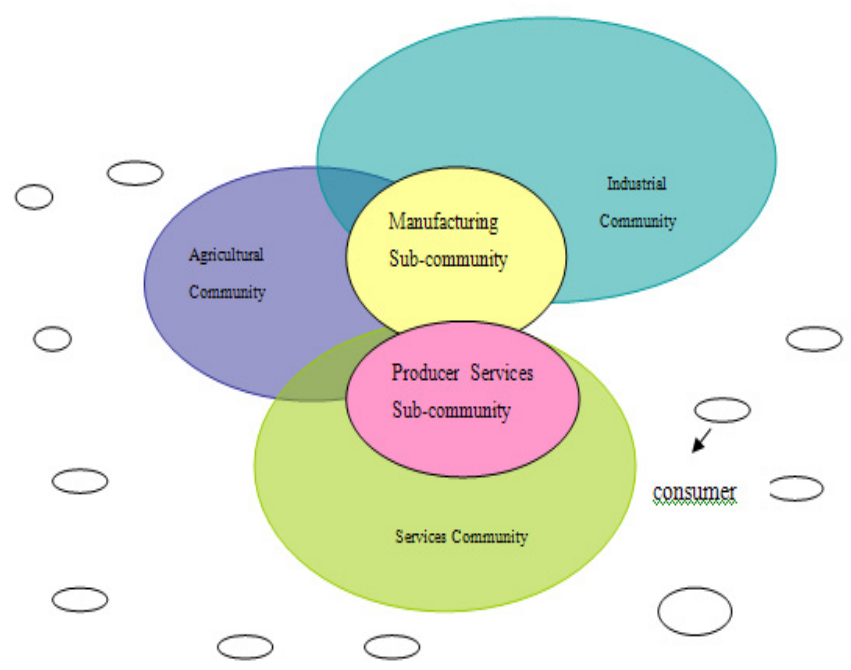

Fig. 2. Composition of the Ecological Community

The fundamental agricultural, industrial and services communities are interacted with each other, the services community being more involved with other communalities. Shelp (1984) pointed out, “Agriculture, excavating and manufacturing are the bricks of the building of economic development with services enterprises being the plaster." Riddle also believes that the services industry contributes to the expansion of other sectors, that they are the adhesive of the economy, providing convenience to the business transaction and impetus to the commodity production and that services are not marginalized or luxurious economic activities but the core of economy. Producer services, as the major part of services, the "adhesive", make it possible for services community to interact and coexist with the other two, forming a organic economic community.

In ecological community of national economy, the labor distribution of manufacturing, outsourcing of services and derivation of industry chain bring about the producer services industry. The upgrade of manufacturing itself requires large quantities of knowledge input, accelerating the development of producer services which, in turn, enhances the competitive power of manufacturing. To summarize, the two industries coexist and develop simultaneously.

Manufacturing sub-community and producer services sub-community can be blended with each other. On the one hand, manufacturing provides a living environment for services in that (1) producer services are derived from manufacturing and (2) manufacturing community are the principal consumers of services. On the other hand, producer services sub-community offer nutrition and knowledge essential to the upgrade of manufacturing. 


\section{$4 \quad$ Roads for the Merging Development of Modern Manufacturing and Producer Services Industry}

There is an inherent evolution mechanism between producer services and manufacturing that is featured by two-way interaction, close correlation and positive feedback. The services play an important role in the upgrading of manufacturing, with their level of development determining that of manufacturing. On the other hand, manufacturing provides momentum and support as in infrastructure for the upgrading of producer services. The paper proposes the following suggestions from the perspective of the interactive development of the two industries.

\subsection{The Hierarchical Level of Manufacturing Should Be Improved So As to Achieve a Positive Interaction with Producer Services}

Many manufacturers in China are invested by foreign capital though China is tuning into the world factory. The manufacturing industry of China mainly follows the mode of international subcontracting, which takes advantage of cheap labor pool in China but cannot cultivate strong competitive power.

As the criteria of international labor division convert from industry levels to value chain levels, the power of a nation lies not in certain industries or products but in the chains or processing stages it holds in the whole industry chain. It is imperative for Chinese manufacturers to improve their hierarchical levels in the industry chain. As for those low-level processing stages, the manufacturers can reinforce their control over logistic purchasing, systematic production and quality control and the like by means of modern information technology. They should also master core technology, enhance their core competitive power and build their own brands. With the deepening of labor division, sectors of producer services have already been merged into every link of manufacturing. Services for the higher hierarchical level of manufacturing involve industry research and feasibility research of investment, product development and design, marketing research and venture capital and etc. Services for the middle level involve quality control, accounting, human resources, law consultancy, information and insurance and etc. Services for the low level include the areas in sales, advertising, logistics, maintenance and clients training, etc. These activities are gradually turning into strategic parts for manufacturers to enhance their power. The integration of manufacturing and producer services can optimize resources and affect the product costs at the lower level. It also merges the shared knowledge and other resources of enterprises to the best, providing powerful momentum for the corporate creation, and contributing to the technology innovation, industry transformation and upgrading of manufacturing (Lin Lei, 2008).

\subsection{The Soft Environment for Producer Services Should Be Optimized, and the Obstacles in System Abolished}

A perfect environment is the important basis on which modern services industry develop. Beside the hardware environment such as modern communications facilities 
and convenient networks, a soft environment including laws and governmental regulations and policies, systems and mechanisms is also indispensable to modern manufacturing. For instance, the government can establish and consummate policies concerning intermediary services agencies of science and technology, support them in finance, subsidies and taxes and aid innovative practices of higher hierarchical level (Sun, 2009). The notion of "Big Market, Small Government" held by Hong Kong government has set us a good example that the government reduces social transaction costs of public services and social integrity, cultivate an open business environment with moderate supervision, and offer enough space for civilian capital in fields of intermediary agencies, shipping and finance, etc.

In addition, the government should regard developing services industry as an important means to promote manufacturing and the living standard of people while drafting macro policies. Regulations that discriminate or restrict the further development of services industries should be abolished in order for services industry to enjoy the same treatment with manufacturing in aspects of investment, market entrance qualifications, governmental financial support, water and electricity supplies. Strict rules regulation over monopoly sectors as telecom and banking, railroad transportation and broadcasting should give way to a competition mechanism and less control over price and investment for enterprises to enter the market freely so as to enhance service quality and efficiency.

\subsection{The Financial Industry as the Core of Cervices Industry Should Be Accelerated and the Industry Code Reinforced}

The services industry with the financial services as the core is the important back-up of the upgrading and development of Chinese manufacturing. Therefore, it is vital to complete the development mechanism of financial services industry, set up and improve regional financial service center and reasonably integrate regional financial resources. One top priority now is to reform regional financial agencies and abrogate obstacles inherent in the system. Favorable conditions should be offered to small and medium-sized manufacturers in applying for loans. Professional corporations offering financial guarantee for small and medium-sized manufacturers could be cultivated step by step to fund these enterprises for their turning into high-tech and capitalintensive ones. For another, various financial innovation mechanisms could be adopted to lower the risks for financial services industry and to improve their efficiency, which will greatly benefit the competitive power of manufacturing in China. What's more, the infrastructure for the financial services industry should be strengthened, so is the financial system of multi-layer and great variety. The initial advance of manufacturing relies to great extent on fund, while enterprises in China have to raise money on their own, deriving only a small sum of capital from financial agencies. Since lack of fund will retard the development of manufacturing on the higher part of industry chain, it is important to broaden the financial channel for manufacturing and create a positive environment for the upgrading of manufacturing.

The intermediary services of science and technology, as a type of technology capital, provide powerful technology support for the upgrading of manufacturing in 
China. As China's economy develops and social labor division deepens, creation initiatives will gradually involve with the upgrading process of manufacturing and exert increasingly great influence. The service quality of intermediary agencies of science and technology should be improved with more coverage of services and a set of qualification evaluation criteria, against the background in which such agencies abound recently. Meanwhile, great efforts should be made to raise practitioners' awareness of service and their professional capacity and morality, preventing the immoral behaviors from happening. Furthermore, compound talents of high level should be admitted into intermediary agencies of services to optimize the personnel structure, which will enable intermediary agencies of science and technology to contribute to the creation system and the whole industry value chain, bringing added value to the industry.

\subsection{More Efforts Should Be Made to Cultivate Talents, Building a Talents Pool for the Further Development of Manufacturing and Services Industry}

The government should give top priority to producer services, lowering the market entrance qualifications, building a sound market for competition and offering favorable treatment in policies. Talents are the most crucial element for the new type, knowledge-intensive producer services industry. So the government is expected to do well in cultivation of needed talents to virtually enhance the efficiency, quality and development level of producer services industry in China, which can be realized through close cooperation of enterprises, universities and research institutes.

The development of services industry and the upgrading of manufacturing require highly professionalized talents. In order to meet such need, more capital should be invested into human resources and cooperation between enterprises and universities should be intensified to cultivate professionals of high level. Besides, measures should be taken to attract overseas professionals, turning China into a real power rich in human capital other than human resources. This calls for complete systems in talents cultivation and movement and creative systems to prevent brain drain. Last, due attention should be paid to the training of competent ordinary laborers and technicians who are also indispensable to the sustainable development and competitive power of manufacturing of China.

\section{References}

1. Baldonado, M., Chang, C.-C.K., Gravano, L., Paepcke, A.: The Stanford Digital Library Metadata Architecture. Int. J. Digit. Libr. 1, 108-121 (1997)

2. Bruce, K.B., Cardelli, L., Pierce, B.C.: Comparing Object Encodings. In: Ito, T., Abadi, M. (eds.) TACS 1997. LNCS, vol. 1281, pp. 415-438. Springer, Heidelberg (1997)

3. van Leeuwen, J. (ed.): Computer Science Today. LNCS, vol. 1000. Springer, Heidelberg (1995)

4. Michalewicz, Z.: Genetic Algorithms + Data Structures = Evolution Programs, 3rd edn. Springer, Heidelberg (1996) 
5. Cohen, S., Zyman, J.: Manufacturing Matters: the Myth of the Post Industrial Economy Basic Books. New York (1987)

6. Rowthorn, P., Ramaswamy, R.: Growth, Trade and Deindustrialization I Mf Staff Papers, pp. 18-41 (1999)

7. Klodt, H.: Structural Change Towards Services: the German Experience University of Birmingham. IGS Discussion Paper (2000)

8. Gurrierp, M.: International Competitiveness in Produces. Paper Presented at the SETI Meeting Room (2003)

9. Pappas, N., Sheehan, P.: The New Manufacturing; Linkage Between Production and Service Activities. In: Sheehan, P., Tegart, G. (eds.) Working for the Future Melbourne, pp. 127-155. Victoria University Press (1998)

10. Karaomerlioglu, D., Carlsson, B.: Manufacturing in Decline? A Matter of Definition Economy, Innovation, NewTechnology, 175-196 (1999)

11. Linyan, S.: Theory and Practice of Service-oriented Manufacturing. Tsinghua University Press, Beijing (2009)

12. Lei, L., Guisheng, W.: The Development of Manufacturing and Services Innovation. Science Press, Beijing (2008) 